Studies in African Linguistics

Vol ume 18, Number 2, August, 1987

\title{
OBJECT AGREEMENT AND TOPICALITY HIERARCHIES \\ IN KIYAKA
}

\author{
Lukowa Kidima \\ University of California, Los Angeles
}

\begin{abstract}
This investigation of object agreement in Kiyaka raises a theoretical question common to Bantu but which has been answered only partially in previous studies: what accounts for the control and sequential order of object agreement markers (OAMs) in languages where the verb complex can take more than one such marker? Individual parameters of topicality hierarchies ( $\mathrm{TH}$ ) have been shown to be responsible for the behaviour of the OAMs, especially in constructions where single hierarchies are active. For $\mathrm{TH}$ to account for conflicting predictions by different individual hierarchies, I propose a Trans-Hierarchical Constraint (THCC) that can be claimed to be cross-Bantu at least. This constraint predicts that OAMs can be determined by a single hierarchy (the predomfnant in the language), or by two hierarchies, one of which must be the semantic one. It follows from the nature of the THCC that there are two types of languages in terms of the strategies they use to resolve conflicting cases:

(1) those where the semantic hierarchy is always active and (2) those where the semantic hierarchy is sometimes inactive. The study also predicts that ambiguity resulting from multiple agreement occurs only when the semantic hierarchy is inactive.
\end{abstract}

\section{Introduction}

Bantu languages share three major characteristics: agglutinative morphology, lexical tone (with the exception of Kikongo, Swahili, and probably a few others), and noun classes. Noun classes play an important role in Bantu verbal agreement. However, not every aspect of verbal agreement in Bantu has received the same amount of attention. For instance, it is common to find at the outset of the study of a Bantu language a list of noun class prefixes and a discussion of how subject-verb agreement (SA) works in the language, but object agreement (OA) may not be mentioned at all. In fact, as can be judged from the recency and number of studies dealing with 
objects in Bantu (see references), the object relation and hence object agreement in Bantu is just being explored. This paper intends to investigate, in some detail, object agreement in Kiyaka, a Bantu language spoken in southwest Zaire and northern Angola.

Like other Bantu languages, Kiyaka exhibits agreement of the verb with subject and object nominals. But object agreement in Kiyaka deserves special attention because it has some special characteristics. For instance, $O A$ in Kiyaka is closely related to the tone pattern of substantives and their information status. That is, an object that agrees with the verb is characterised by a typical tone pattern, which I have associated with arguments whose participants represent old information; these participants are identifiable because they are given by previous discourse or by the context. More important, object agreement has some interesting implications for the word order of simplex clauses.

While the major objective of this paper is descriptive, I will also address some theoretical problems raised by the data. Section 1 presents a brief description of facts relevant to $O A$. These include a discussion of the noun class system and its role in agreement, the different ways $O A$ is marked, the constituents which can trigger $\mathrm{OA}$, and the co-occurrence of $\mathrm{OA}$ markers (OAMs). In section 2, I suggest an analysis which will account for the complications resulting from multiple agreement. The first complication concerns the competition for the control of the OA prefix (OAP) when all the object nominals to agree with the verb require prefixation in order to satisfy the discourse requirements. The analysis will be based on the functional notion of topicality hierarchies, which has provided insights in accounting for $\mathrm{OA}$ as well as for other rules in Bantu, e.g. Passivisation and Relativisation. Specifically, I will argue that the OAP is controlled by the nominal whose semantic role is higher on the semantic hierarchy Benefactive $>$ Recipient > Patient.

The second complication concerns the clash which results when two hierarchies make conflicting predictions. Hierarchies such as the person hierarchy $(\mathrm{PH}) 1>2>3$ and the animacy hierarchy (AH) Human > Animate > Inanimate have been shown to be relevant for OA in Bantu. Moreover, these hier- 
archies can contradict the predictions made by the semantic hierarchy. In order to account for conflicting co-occurrences of OAMs for Kiyaka, I propose a Trans-Hierarchical Consistency Constraint (THCC). The analysis proposed to account for conflicting co-occurrence of OAMs in Kiyaka will be extended to Shambala and Haya, previously investigated by Duranti [1979] as to how they resolve conflicting predictions made by different hierarchies. I will attempt to show that the two unrelated strategies that Duranti suggested for Shambala and Haya can be successfully replaced by the one solution proposed for Kiyaka. On the basis of the assumptions behind the THCC, I further hypothesise that languages which exhibit these conflicting cases can be divided into two different types with regard to the strategies they use to resolve conflicting cases. I will try to demonstrate that all languages use a version of the THCC. Kiyaka-type languages (type 1) use the strong version, i.e. at least two hierarchies, one of which must be the semantic hierarchy, are active; Haya-type (type 2) langauges use the weak version (only one hierarchy is active). Finally, it is shown that ambiguity resulting from multiple $O A$ can be predicted without reference to specific sentences or language: type 1 languages do not allow ambiguity since the semantic hierarchy is always active in these languages; however, ambiguity is very frequent in type 2 languages, since another hierarchy takes precedence over the semantic one in those languages.

\section{Description}

1.1. Noun classes and verbal agreement. As is common in Bantu languages, Kiyaka has noun classes (18 according to Van den Eynde [1968]). Each of them is associated with a set of prefixes that signal grammatical agreement between a modifier and its head noun or between a verb and its subject or objects(s). Sentence (1) below illustrates both subject and object agreement with the verb.
(1) ba-aná ba- $\mathrm{n}^{\prime}-$ súumb-idi khoombó
2child SAthey-OAit-buy-P
'the children bought the goat' 
In (1) $\mathrm{SA}^{\mathrm{l}}$ is marked by prefixing the verb stem with ba-, which is identical to the prefix attached to the noun stem to form the noun baaná 'children'. $O A$ is shown by the syllabic $n^{\prime}$ - occurring between the SA prefix ba- and the verb stem suúmb- . The OA marker agrees in class with the object noun it indexes: both khoombó and $n^{\prime}$ - are class 1 , as can be seen in the table on the next page.

Table 1 presents the different agreement markers in Kiyaka. Columns 1 and 2 1ist, respectively, the noun and modifier prefixes for each class. Columns 3 to 6 give the markers for verbal agreement; i.e. subject agreement (column 3), and object agreement (columns 4 to 6). /N'/ means a syllabic nasal prefix which assimilates to the following segment and $/ N /$ symbolises a non-syllabic nasal prefix that generally causes the modification of the stem initial segment (see stem change in 1.3). A dash (---) signals a morphological gap.

1.2. Object agreement and information status. As was shown in Kidima [1983, 1984], Kiyaka has a pragmatic tone. ${ }^{2}$ That is, it is possible to tell just from the tone if a noun is new or old information. I consider new information the nominal which answers a genuine WH-question. This is consistent with the statement by Clark and Clark [1977:368] that "in an appropriate answer, the wanted fact should appear as new information." If we apply this test to Kiyaka simplex clauses, we notice that the question answering nominal is characterised by a tone pattern distinct from the one the noun would

${ }^{1}$ Symbols and abbreviations:

$\begin{array}{llll}\text { A } & \text { Aspect } & \text { Rec } & \text { Recipient } \\ \text { SA } & \text { Subject agreement } & \text { Ben } & \text { Benefactive } \\ \text { OA } & \text { Object agreement } & \text { Loc } & \text { Locative } \\ \text { PR } & \text { Present } & \text { Instr } & \text { Instrumental } \\ \text { OAP } & \text { Object agreement prefix } & \text { AH } & \text { Animacy hierarchy } \\ \text { OAM } & \text { Object agreement marker } & \text { HH } & \text { Humanness hierarchy } \\ \text { App1/APP } & \text { Applicative suffix } & \text { NH } & \text { Number hierarchy } \\ \text { P/PST } & \text { Past } & \text { PH } & \text { Person hierarchy } \\ \text { Pat } & \text { Patient } & \text { SH } & \text { Semantic hierarchy }\end{array}$

Figures in the glosses indicate the noun class number.

${ }^{2}$ Only $\mathrm{H}$ tone is marked by an acute accent; low tone is not marked. 
Table 1. Noun prefixes and corresponding agreement markers in Kiyaka

\begin{tabular}{|c|c|c|c|c|c|c|c|}
\hline \multicolumn{2}{|c|}{ Class } & \multirow{2}{*}{$\begin{array}{l}\text { Noun } \\
\text { Prefix } \\
\emptyset \\
\emptyset \\
/ N^{\prime} /, \text { mu-, } \emptyset\end{array}$} & \multirow{2}{*}{$\begin{array}{l}\text { Modifier } \\
\text { Prefix } \\
u-, \emptyset \\
u-, \emptyset \\
u-, \emptyset\end{array}$} & \multirow{2}{*}{$\begin{array}{l}\text { SA } \\
\text { Prefix } \\
/ N /, i- \\
u-, \emptyset \\
k a-, u-, \emptyset\end{array}$} & \multirow{2}{*}{$\begin{array}{l}\text { OA } \\
\text { Prefix } \\
\text { /N/ } \\
\text { ku- } \\
\text { /N'/ }\end{array}$} & $\begin{array}{l}\text { OA } \\
\text { Enclitic } \\
---\end{array}$ & $\begin{array}{l}\text { OA } \\
\text { Full pr }\end{array}$ \\
\hline 1 & $\begin{array}{l}1 s g \\
2 s g \\
3 s g\end{array}$ & & & & & $\begin{array}{l}--- \\
--- \\
---\end{array}$ & $\begin{array}{l}--- \\
--- \\
\text { yaand } i\end{array}$ \\
\hline $2 a$ & $\begin{array}{l}1 \mathrm{p} 1 \\
2 \mathrm{p} 1 \\
3 \mathrm{p} 1\end{array}$ & $\begin{array}{l}\text { ba- } \\
\text { ba- } \\
\text { ba- }\end{array}$ & $\begin{array}{l}\text { ba- } \\
\text { ba- } \\
\text { ba- }\end{array}$ & $\begin{array}{l}\text { tur } \\
\text { lu- } \\
\text { ba- }\end{array}$ & $\begin{array}{l}\text { tu- } \\
\text { lu- } \\
\text { ba- }\end{array}$ & $\begin{array}{l}--- \\
--- \\
---\end{array}$ & $\begin{array}{l}--- \\
--- \\
\text { yaawu }\end{array}$ \\
\hline 3 & & $/ N^{\prime} /, \mathrm{mu}-$ & u- & u- & --- & SAta & SAtaawu \\
\hline $\begin{array}{l}4 \\
5\end{array}$ & & $\begin{array}{l}/ N^{\prime} /, \mathrm{mu}- \\
\mathrm{di}-\mathrm{O}\end{array}$ & $\begin{array}{l}\mathrm{mi}- \\
\mathrm{di}-\end{array}$ & $\begin{array}{l}\mathrm{mi}- \\
\mathrm{di}-\end{array}$ & --- & $\begin{array}{l}\text { SAta } \\
\text { SAta }\end{array}$ & $\begin{array}{l}\text { SAtaawu } \\
\text { SAtaawu }\end{array}$ \\
\hline 6 & & ma- & ma- & ma- & --- & $\mathrm{SA}+\mathrm{a}$ & SAtaan \\
\hline 7 & & $\mathrm{kl}-$ & ki- & $\mathrm{ki}-$ & --- & SA+a & SAtaah \\
\hline 8 & & bi- & bi- & bi- & --- & SAta & SAtaaw \\
\hline 9 & & $/ \mathrm{N} /$ & $i-$ & $\mathrm{i}-$ & $-\infty$ & $\mathrm{SA}+\mathrm{a}$ & SAtaaw \\
\hline 10 & & $/ \mathrm{N} /$ & $z i-$ & $z i-$ & --- & $\mathrm{SA}+\mathrm{a}$ & SAtaaw \\
\hline 11 & & lu- & Iu- & Iu- & --- & $\mathrm{SA}+\mathrm{a}$ & SAtaaw \\
\hline 12 & & ka- & ka- & ka- & --- & $\mathrm{SA}+\mathrm{a}$ & SA+aaw \\
\hline 13 & & tu- & tu- & tu- & --- & $\mathrm{SA}+\mathrm{a}$ & SA+aaw \\
\hline 14 & & bu- & bu- & bu- & --- & $\mathrm{SA}+\mathrm{a}$ & SA+aaw \\
\hline 15 & & ku- & ku- & ku- & --- & $\mathrm{SA}+\mathrm{a}$ & SAtaawu \\
\hline 16 & & ha- & ha- & ha- & --- & $\mathrm{SA}+\mathrm{a}$ & SAtaaw \\
\hline 17 & & ku- & ku- & ku- & --- & SAta & SAtaawu \\
\hline 18 & & mu- & mu- & mu- & --- & $\mathrm{SA}+\mathrm{a}$ & SAtaawu \\
\hline
\end{tabular}

bear if it was not asserted. This tone pattern can be observed with khóombo of $(7 \mathrm{a}, \mathrm{b})$. This $\mathrm{H}$ tone associated with new information is realised on the stem initial mora for these nouns. When a noun bearing this tone pattern occurs immediately next (before or after) to its verb, both make up a phonological word characterised by tone spreading. Such a noun is focused or asserted.

In (3), we see the noun khoombó with a $\mathrm{H}$ tone on the last mora. This is the tone pattern associated with old information. An old information noun is to be understood in Chafe's [1976] sense. Such a noun represents a specific and definite participant that is identifiable from previous mention in the discourse or from context. This is the situation where the OA occurs. 01d information nouns are sometimes referred to as topical since they are generally peripheral to the clause or $S: \mathrm{NP}_{1} \mathrm{~s}\left[\ldots \mathrm{M}_{1}-\mathrm{V} \ldots\right]$ or 
$\left.\mathrm{s}^{[\ldots .} \mathrm{OM}_{i}-\mathrm{V} \ldots\right] \mathrm{NP}_{i}$. These are the structures in which Kiyaka object agreement occurs and we see that they match the structures suggested by Givón [1976] for left and right dislocation, respectively. According to Givón, these two structures are instrumental in the development of the $O A$ in Bantu.

As to the function of $O A$, it has been shown that OA in Bantu signals that the indexed-argument is definite, topical, or given. (Detailed discussion can be found in Givon [1976], Trithart [1979], and Hyman and Duranti [1982] and sources cited there.) ${ }^{3}$ In fact, non-subject arguments which agree with the verb in Kiyaka, and in Bantu in general, are characterised by a high degree of individuation, in Hopper and Thompson's [1980] sense. This accounts for the fact that non-subject proper nouns in Kiyaka have to agree with the verb unless they are focused and/or marked by a preposition. Consider (2):
(2) a. tu-n'-telelé
Maafú
'we called Maafu'
SAwe-OAher-cal1-P 1-
b. *tu-telelé Maafú

In (2) we have an object argument whose referent is highly individuated. Maafú is a proper noun and is referential, definite, identifiable, and specific. It cannot have a non-referential or generic meaning, and (2b) is therefore ungrammatical. In (3a), khoombó 'goat' is also referential. However, khoombó can be non-specific and generic when it is not focused ( $3 \mathrm{~b}$ ). That is possible because khoombó is common and non-human, as opposed to Maafú, which is proper and human. Sentence (3b) is good, unlike (2b), because Maafú must agree with the verb while khoombó does not have to.
b. baaná ba-suúmbidi khoombó 2child SAthey-buy-P lgoat
(3) a. ba-aná ba- $n^{\top}-$ súumb-idi 2child SAthey-OAit-buy-P lgoat
'the children bought the goat'
'the children bought a/the goat'

${ }^{3}$ Givón [1976] does show, however, that the OM In Swahili can index an indefinite object. He states that in the development of the OM in Bantu languages, which originally had no specific definitizer, Swahili has gone one step further than most of the Bantu languages. 
There is a significant discourse difference between (3a) and ( $3 b$ ). Although both require contextual information for an appropriate interpretation, (3a) presupposes that the context is known, e.g. we have talked about the goat; (3b) has no clues as to the context. The consequence is that ( $3 a$ ) is understood as a follow up of a previous interaction. However, (3b) is interpreted as a piece of narrative whose discourse frame is missing, suggesting that non-specific and generic objects probably constitute an important characteristic of narrative in Kiyaka. A phrase 1ike "At that moment, ..." or "When they arrived at the market, ..." could make a perfect frame for ( $3 b$ ). (I have used "frame" in Clark and Clark's [1977] sense).

As to the alternation between [-Foc] vs [+Foc] or [-Prep] vs [+Prep], I will assume that it is controlled by pragmatics. For instance, a nominal like a benefactive is obligatorily marked by a preposition when it is not focused. However, when the same nominal is focused (placed immediately before or after the verb), it is preferably prepositionless. The preposition or focusing as ways of marking an asserted or new information argument do not co-occur and are thus in complementary distribution. This mutual exclusiveness suggests that they both play the same discourse (semantic) function. Let us now explore the different ways of marking object agreement in Kiyaka.

1.3. Marking $0 A$. There are three different ways to index agreement with an object nominal in Kiyaka. Agreement between the verb and a nominal can be marked by a prefix, an enclitic, or a full pronoun.

1.3.1. Prefix. An $O A$ prefix is placed immediately before the verb stem. This process is reserved for nouns in class 1 or 2 , which generally comprise animate nouns. Prefixation in (4) is realised by the occurrence of $-n^{\prime}-$ before the verb stem (tel-) . Only one object prefix is possible.

(4) a. tu-n'-tel-elé mwaaná (betó) 'we called the child' SAwe-OAhim-call-P 1-child we

When the prefix is a first person singular, the initial segment of the verb stem is modified, as 'shown in (4b), where the verb stem is -tel- 'to call'. (4) b. baaná ba-thél-ele (mené) 'the children called me' 2child SAthey-0Ame-cal1-P 1me 
The full pronoụn mené 'me' is optional here. When stem change occurs, stem initial fricatives become affricates, voiced non-fricatives become homorganic prenasalised stops, and voiceless stops become aspirated.

Compare (4b) with (4c). Here, the full pronoun méné 'me' is focused and obligatory; the verb appears without any modification.
(4) c. baaná méné bá-tél-ele
'the children called ME'

2child me SA2-cal1-RP

1.3.2. Enclitic. When the verb agrees with a nominal object in a class higher than 2; the agreement marker is an enclitic.
(5) baaná ba-suúmb- $\{d f-k y a ́ ~ k i t \uparrow$
2child SA2-buy-RP-OA7 7chair
'the children bought the chair'

Enclitics are generally short forms of pronouns, composed of a prefix and the short form of a pronoun stem. In Kiyaka, the prefix is identical to the SA prefix for that class. The enclitic kya in (5) is composed of $k i-$, which is the SA prefix for class 7, and $-a$, the short form for the pronoun stem -aawu. Only one enclitic is possible on a verb.

1.3.3. Full pronoun. When the standard morphological device (prefixation or encliticisation) is not available, $1 . e$. it is already used by another marker), a full pronoun acts as an object agreement marker. The pronoun immediately follows the verb and can index agreement with an object of any class. The full pronoun which acts as an agreement is obligatory. The example in (6) shows the pronoun yaándi 'him' indexing mwaaná 'child'.
(6) $\begin{aligned} & \text { tu-ku-hitik-idi } \\ & \text { SAwe-0Ayou/p-send-RP }\end{aligned}\left\{\begin{array}{l}{ }^{\star} \emptyset \\ \text { yaándi } \\ \text { 1him }\end{array}\right\} \begin{aligned} & \text { mwaaná (ngé) } \\ & 1 \text { child }\end{aligned}$
'we sent you the child'

1.4. What constituents can determine $0 A$ ? In this section I examine the types of constituents that can determine $0 A$. - It will be demonstrated that $O A$ in Kiyaka can in principle be controlled by any non-agent constituent, provided it is old information. I show in this section that when this discourse condition is met, a patient, a recipient, and a benefactive noun can determine $O A$ with the verb. Agreement is also possible with prepositional 
phrases containing nominals such as a recipient, but this will not concern us for the moment.

1.4.1. Patient. A patient in Kiyaka is not marked by a preposition. It occurs immediately before or after the verb when it is focused and represents new information.' Sentence (7a) illustrates a patient in preverbal new Information or focus position, and (7b) shows a patient in a postverbal focus position. Object agreement is impossible when the patient is focused, indefinite, or new information. This is shown by the ungrammaticality of (7c d). (Constituents in capital letters are focused.)

$\begin{array}{ll}\text { (7) a. taatá khóómbó kásúúmbldi } & \text { 'father bought A/THE GOAT' } \\ \text { father lgoat SAhe-buy-P } & \text { 'father bought A/THE GOAT' } \\ \text { b. taatá suúmbídí khóombo } & \\ \text { father buy-P lgoat } & \text { 'father bought a goat' } \\ \text { c. *taatá khómbó ká-n'-súúmb-idi } & \text { 'father bought a goat' } \\ \text { d. *taatá n'-suúmb ld l khóombo } & \end{array}$

When a patient is old information, an OAM shows up in the verbal unit. In this case, the patient does not have a strict position in the clause, i.e. its occurrence is relatively free. In (8), the verb agrees with the object. Agreement is indicated by the presence of $-n^{\prime}-$, which agrees with the noun khoombó 'goat' in class, before the verb stem.
(8) a. taatá n'-súumb-idl khoombó father 0Al-buy-RP lgoat
'father bought the goat'
b. taatá khoombó n'-súumbldi
c. khoombó taatá n'-súumbidi
d. khoombó n'-súumbidi taatá
e. n'-súumbidi taatá khoombó
f. $n^{\prime}$-súumbidi khoombó taatá

The free word order that (8) exhibits is not possible when the object does not agree with the verb, as indicated by the ungrammaticality of (9).
(9) *khoombó taatá súumbidi lgoat father buy-RP

'father bought the goat'

(9) is ill-formed because the object may not precede its verb unless it is 
focused or agrees with the verb.

1.4.2. Recipient. A recipient is generally marked by the preposition kwa 'to' when it is not focused $(10 \mathrm{a})$. The preposition kwa is generally optional when the recipient is in focus (placed immediately before the verb). However, it cannot even occur with certain verbs, including the one in this example (10b). The recipient cannot agree with the verb when it is marked by kwa (10c) or when it is in focus (10d).

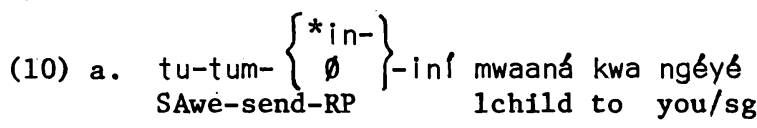

'we sent the child to you'

b. $\left\{\begin{array}{l}{ }^{*} k w a \\ \emptyset \\ \text { to }\end{array}\right\} \begin{aligned} & \text { ngéyé tú-túm-in-inf mwaaná } \\ & \text { you/s SAwe-send-app1-P.1-child }\end{aligned}$

'we sent $a /$ the child to YOU'

c. *tu-ku-tum-in-iní mwaaná kwa ngéyé

'we sent the child to you'

d. *kwa ngéyé tú-kú-túm-in-ini mwaaná

'we sent YOU a/the child'

But when the recipient is old information and prepositionless, it agrees with the verb.

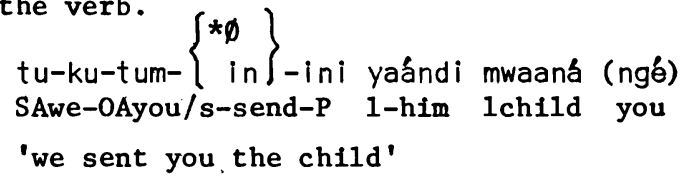

The applicative suffix is obligatory when the recipient agrees with the verb or when it is focused, whereas it cannot cooccur with the recipient marked by kwa $(10 \mathrm{a}, \mathrm{b})$. Finally, the whole recipient prepositional phrase can be indexed on the verb. In this case, agreement is with the preposition kwa, which therefore determines the form of the enclitic, as can be seen in (12).

(12) tu-n'-hitikidi-kwá mwaaná kwa Maáfu

SAwe-1him-send- $\overline{\mathrm{P}-17}$ 1child $\overline{17-t o}$ Maafu

'we sent the child to Maafu('s)' 
This construction is however rarely used with the recipient meaning. The kwa- phrase in (12) is easily interpreted as a locative phrase, as can be judged by the locative class prefix (class 17).

1.4.3. Benefactive. In general, a benefactive that is not focused does not appear bare. There is no single word preposition to mark an unfocused benefactive in Kiyaka; rather, it is marked by the phrase mu dyaambu dya, which 1iterally means 'for the reason of'. The ungrammaticality of $(13 c, d)$ makes the point that the benefactive may not agree with the verb if it is marked by 'for' or if it is focused.

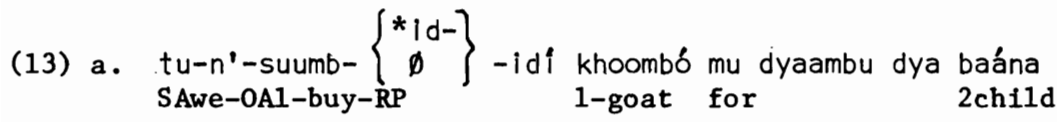

'we bought the goat for the children'

b. (mu dyaámbú dyá) báaná tú-h-súúmb $\left\{\begin{array}{l}* \emptyset \\ -1 d\end{array}\right\}-1$ di khoombo

'we bought the goat for the children'

c. *tu-ba-suumb-id-idí khoombó mu dyaambu dya baána

'we bought the goat for the children'

d. *mu dyaámbú dyá bááná tú-bá-súúmb $\left\{\begin{array}{l}* \emptyset \\ -l d\end{array}\right\}-$ ld l khoombó

'we bought the goat FOR THE CHILD'

When the benefactive is old information and prepositionless, it can agree with the verb (14).

(14) tu-ba-sumb $\left\{\begin{array}{l}* \emptyset \\ -i d\end{array}\right\}$-idi yaándi baaná khoombb

SAwe-OA2-buy-app1-RP lit 2child lgoat

'we bought the children the goat'

Again we see that the applicative suffix is not acceptable when the benefactive is unfocused and marked with 'for' (13a), but it is obligatory when the benefactive is focused (13b) or agrees with the verb (14).

1.5. Co-occurring object agreement markers. In Kiyaka, a verb can agree with more than one object nominal. Multiple agreement is carried out with- 
out any problem when each of the nominals requires a different morphological process in order to be indexed on the verb. In (15) below, the verb agrees with three objects: the patient, baana, by prefixation; the first person singular benefactive by the stem change; and the directional, ku zaandú, by encliticisation.

(15) taatá u-ba-thúm-ln-lnl-kwa ku zaandú baaná (mené) Ifather SAhe-OA2-OAme-send-app1-RP-OA17 17to market 2child 1me

'father sent the children to the market for me'

A complication arises when the nominals to be indexed require the same morphological operation. For instance, if a clause contains a patient and a non-first person singular benefactive both from class 1 , the $0 A$ markers referring to these two nominals must occupy the prefix slot, which can take only one OA marker, so a competition develops for the control of the prefix slot. In the discussion below, I will examine conflicting co-occurrences of OA markers. As I showed in Kidima [1984], the enclitic slot is not involved in the type of competition characteristic of the prefix slot, which raises some theoretical questions. Therefore, the discussion of conflicting co-occurrences of OA markers will exclusively concern the prefix slot.

As noted above, the prefix slot is reserved for object markers that index nouns of classes 1 and 2, which generally comprise animate nouns. In terms of semantic roles, the prefix slot can be occupied by markers which index benefactives, recipients, and patients. I will consider the different possible conflicting co-occurrences of these nominals.

1.5.1. Benefactive-Patient. When both a benefactive and a patient are old information and the benefactive lacks a preposition, the prefix slot is occupied by the marker that refers to the benefactive nominal, as shown in (16a). tu-n'-tel-el-ele yaáwu baaná taatá SAwe-0Ahim-cal1-app1-p 2-them 2-child 1-father

'we called the children for father'

b. *tu-ba-tel-el-ele yaándi baaná taatá 'we called the children for father' 


$$
\begin{aligned}
& \text { c. tu-ba-tel-elé baaná mu dyaambu dya taáta } \\
& \text { SAwe-0Athem-call-P 2child for lfather } \\
& \text { 'we called the children for father' }
\end{aligned}
$$

Sentence (16b) is ungrammatical because the patient may not determine the prefix when the benefactive is old information and bare. Prefixation of the patient is only possible when the benefactive does not agree with the verb. This can be observed in (16c), where the patient baana controls the prefix and the benefactive taáta is marked by mu dyaambu dya. Note that when the benefactive controls the prefix, the patient is indexed obligatorily by a full pronoun ( yaáwu in (16a)).

1.5.2. Recipient-Patient. If both a recipient and a patient are candidates for an $O A$ prefix, the recipient determines the prefix, while the patient is obligatorily indexed by a full pronoun (17a).

(17) a. tu-n'-hitik-idi yaáwu baaná Maafú

SAwe-OAher-send-P 2them 2child 1Maafu

'we sent Maafu the children'

b. *tu-ba-hitik-idi yaándi Maafú baaná

SAwe-OAthem-send-P 1her 1Maafu 2child

'we sent Maafu the children'

c. tu-ba-hitik-idí baaná kwa Maáfu

SAwe-0Athem-send-P 2child to 1Maafu

'we sent the children to Maafu'

The patient cannot control the prefix when the recipient is old information and bare. This explains why $(17 b)$ is ungrammatical. In (17c), the patient, baaná, controls the prefix ba- because the recipient nominal, Maffu, is marked by the preposition kwa.

1.5.3. Benefactive-Recipient. When a benefactive and recipient compete for the OA prefix slot, the benefactive prevails, as indicated in (18a). The recipient is obligatorily indexed by a full pronoun yaándi .

(18) a. n'kaandá tu-ba-hitik-id-idí-wá yâándi Maafú baaná

3-1etter SAwe-OAthem-app1-P-OA3 1-her 1-Maafu 2child

'we sent Maafu the letter for the children' 
b. * $n^{\prime}$ kaandá tu-n'-hitik-id-idl-wá yááwu baaná Maafú

3-1etter SAwe-OAher-send-app1-P-OA3 2them 2child 1Maafu

'we sent Maafu the letter for the children'

c. tu-n'-hitik-idi-wá n'kaandá Maafú mu dyambu dya baána

SAwe-OAher-send-P-OA3 3book 1-Maafu for 2child

'we sent Maafu the letter for the children'

The recipient Maafú cannot control the prefix when the benefactive is old information and bare, as can be observed by the ungrammaticality of (18b). Again, the recipient can determine the prefix when the benefactive is not bare $(18 c)$.

1.5.4. Benefactive-Recipient-Patient. In the event of conflicting co-occurrence of a bare benefactive, recipient, and patient, only the benefactive can be indexed by prefixation, as illustrated in (19a).

(19) a. baaná tu-ba-hitik-id-idi yaáwú yáándi bambwá Maafú

2child SAwe-OAthem-send-app1-P 2them 1her 2dog 1-Maafu

'we sent Maafu the dogs for the children'

b. *Maafú tu-n'-hitik-id-idi yaáwú yáándi bambwá baaná

1-Maafu SAwe-OAher-send-app1-P 2them 1her 2dog 2child

'we sent Maafu the dogs for the children'

c. *bambwá tu-ba-hitik-id-idi yaáwú yáándl baaná Maafú

2-dog SAwe-OAthem-send-app1-P 2them 1her 2child 1-Maafu

'we sent Maafu the dogs for the children'

Sentences $(19 b, c)$ show that when the benefactive is bare, neither the recipient (19b) nor the patient (19c) can determine a prefix.

The facts of object agreement described above clearly require some explanation. In the following section $I$ will suggest an analysis based on the discourse notion of topicality hierarchies. The analysis will focus on developing a more general use of the hierarchies. In order to achieve this goal, I will put more emphasis on the things that using these hierarchies have in common, rather than what differentiates them.

In the analysis I present in the following section, I rely on the semantic hierarchy developed by Foley and Van Valin [1984]. But the terms I use 
for the different semantic case roles do not always conform with Foley and Van Valin's system. For instance, the non-agent arguments for a verb like hitika 'send' in (19) should preferably be termed "locative" for Maafu and "theme" for bambwa. Instead, I have used "recipient" and "patient", respectively. That is only in order to be consistent with the terms used in Duranti [1979], which I will be referring to in most of the following section.

\section{Analysis}

2.0. Introduction. It has been demonstrated on more than one occasion that topicality hierarchies account most adequately for facts relevant to object agreement in Bantu, e.g. Hawkinson and Hyman [1974], Duranti [1979], Hyman and Duranti [1982]. I will argue in this section that OA in Kiyaka is also sensitive to these hierarchies. In particular, I will show that the hierarchy of semantic roles (Ben > Rec > Pat) takes care of all cases where competition develops for the control of the OA prefix.

In addition, I will examine the interaction between different hierarchies. Specifically, I will discuss how the semantic hierarchy (SH) interacts with the finer hierarchies, such as the person hierarchy ( $\mathrm{PH})$, the number hierarchy $(\mathrm{NH})$, and the humanness hierarchy $(\mathrm{HH})$. The discussion in this section will also include the spectal case of the interaction between the semantic hierarchy and the morphological division between class $1 / 2$ and other classes, which corresponds to prefixation and encliticisation respective1y. Later in this section, the analysis suggested for Kiyaka will be extended to Shambala and Haya, on the basis of data from Duranti [1979].

2.1. Control of the prefix. We have seen in the examples (16), (18), and (19) that the benefactive always prevails whenever it is involved in a competition for the control of the OAP. These constructions are correctly predicted by the hierarchy of semantic roles in (20), adapted from Foley and Van Valin [1984], shown on the next page.

As to the reason why the benefactive prevails whenever there is competition for the control of the OAP, it suffices to say that in the selection of UNDERGOER, the patient is unmarked, the recipient or theme is next marked 


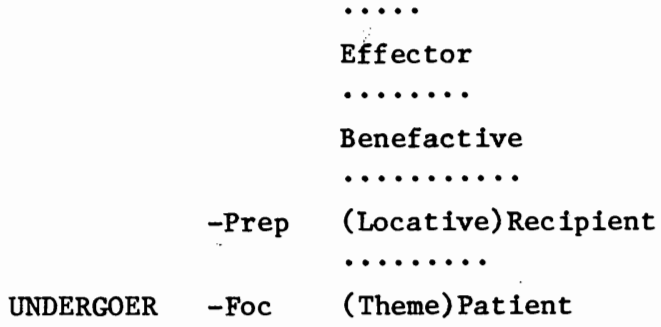

and the benefactive is the most marked. So it appears that the OAP is controlled by the nominal the most marked for the selection of the undergoer. Incidentally, the iconic principle seems to be at work here: the benefactive is marked by a whole phrase (mu dyaambu dya) and not by a single word as is the case for the recipient (kwa).

The marked character of the benefactive is further revealed by the occurrence of the applicative suffix -il-, which signals that a nominal not subcategorised for the basic verb (a "satellite" in Dik's [1980:9] terms) has been added to the predicate frame. This valence-increasing role of the applicative has been elaborated in Marantz [1984], following Kisseberth and Abasheikh [1977]. In addition, Marantz argues that the applicative affix is the role (case) assigner for the benefactive nominal. I will assume this part of Marantz's analysis for Kiyaka. In so doing, I can account for the fact that the prepositional phrase mu dyaambu dya and the applied suffix -il- are in complimentary distribution. In effect, 'for' and the applicative generally do not co-occur (see (11) and (12)), which suggests that they presumably play the same role. The final observation to make is that the applicative in Kiyaka is always required when the corresponding nominal is either the topic or in focus.

2.2. Interaction between hierarchies. As I mentioned in the introduction, several other hierarchies have been shown to be active in Bantu object agreement, in addition to the semantic hierarchy. These different hierarchies make different and sometimes conflicting predictions. It is only reasonable to expect, however, that an adequate analysis of $\mathrm{OA}$ will be able to predict 
the outcome of such conflicting predictions.

Durant1 [1979] presents the first and (to my knowledge) the only attempt to uncover the principles which account for potential conflicting predictions of different hierarchies. In that paper, Duranti (henceforth D) discussed data from Shambala and Haya. In this section, I will first investigate conflicting predictions in Kiyaka. Then, I will examine how the Shambala and Haya data fit into the proposal I make for Kiyaka.

2.2.1. Kiyaka. In Kiyaka, there are clear cases where the predictions made by the semantic hierarchy are not respected. Such a case is illustrated in the examples below, where the prediction that the benefactive should control the OAP is countered by the presence of another relevant or active hierarchy, the person hierarchy $(\mathrm{PH})$.
(21) a. ba-tu-tél-él-élé yáándl mwaaná
SAthey-OAus-call-appl-P $1 \mathrm{him}$ 1child
1 Ben \& 3 Pat
'they called the child for us'
b. *ba-n'-tél-él-élé bééto mwaaná
'they called us for the child'
3 Ben \& 1 Pat
*Pref: Ben
c. (mu dyaámbu dyá) mwááná bá-tú-tél-él-élé (betó)
for 1child SAthey-OAus-call-appl-P us
'they called us for the child'
(22)
a. ba-ku-tél-él-élé yáándi mwaaná
SAthey-0Ayou/s-call-app1-P 1him . 1child
2 Ben \& 3 Pat
'they called the child for you'
b. *ba-n'-tél-él-élé ngéyé mwaaná
3 Ben \& 2 Pat
'they called you for the child'
*Pref : Ben
$\begin{array}{ccc}\text { c. (mu dyaámbú dyá) mwááná bá-kú-tél-él-élé } & \text { (ngé) } \\ \text { for } & \text { lchild SAthey-OAyou/s-app1-P-call you }\end{array}$
'they called you for the child'

(23) a. ba-ku-thél-él-élé (ngé)

1 Ben \& 2 Pat

SAthey-OAyou/s-cal1-app1-P you

Pref: Ben

'they called you for me' 


$$
\begin{aligned}
& \text { b. *ba-thél-él-élé ngéyé (mené) } \\
& \text { 'they called me for you' } \\
& \text { c. (mu dyaámbú dyá) ngéyé bá-THél-él-élé \& } 1 \text { Pat } \\
& \text { for you/s SAthey-OAme-call-appl-P me } \\
& \text { 'they called me for you' }
\end{aligned}
$$

In (2ib), (22b), and (23b) the benefactive cannot control the OAP. This situation is created by the interaction between the semantic role hierarchy and the person hierarchy $(1>2>3)$. Specifically, this clash obtains since the semantic hierarchy predicts that the benefactive should control the OAP. At the same time, the person hierarchy predicts that the OAP should be controlled by the 1st person in (21b) and (23b) and by the 2nd person in (22b). Unfortunately, the insightful hierarchy in (20) does not say much concerning the solution to this clash between the two hierarchies.

It is crucial to recognise that each position on the semantic role hierarchy can be subdivided into a smaller hierarchy, e.g. the Person Hierarchy. That is, an agent or a patient can be first, second, or third person. This sort of internal hierarchy of each position interacts with the semantic role hierarchy in some rules of some languages. This is exactly the case for $O A$ in Kiyaka. Instead of showing the person hierarchy at every semantic position, I represent it as shown in (24).

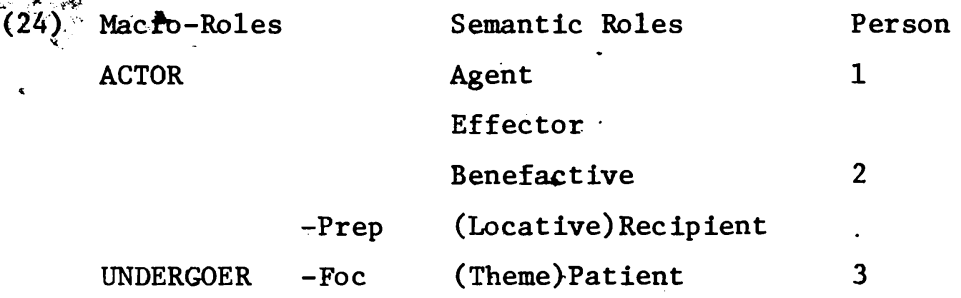

Using (24), I suggest that the facts described in (21) through (23) result from the failure to comply with a constraint on the selection of features from two different hierarchies. Specifically, the (b) sentences in the examples above are not grammatical because the lines that 1 ink the different positions on each hierarchy cross. Sentence (2la) is good since the high position of the benefactive compared to the patient is preserved on 
both hierarchies. In (22b) the line which links the benefactive to 3 crosses the one 1 inking patient to 1 , and the resulting construction is ungrammatical. The same explanation holds for both (22) and (23). In (22a), the line linking benefactive to 2 does not cross that linking patient to 3 : the sentence is good. However, the line from benefactive to 3 and that from patient to 2 cross, causing the ungrammaticality of (22b). The benefactive links to a position higher than that which the patient links to in (23a): the resulting sentence is grammatical. But the benefactive links to a position lower than that to which the patient links in (23b), therefore, the result is 111-formed. These predictions can be schematically presented as in $\left(21^{\prime}\right)-\left(23^{\prime}\right)$. The (a) or grammatical sentences of (21)-(23) are represented by the non-crossing solid lines and the (b) sentences by the crossing broken 1ines.
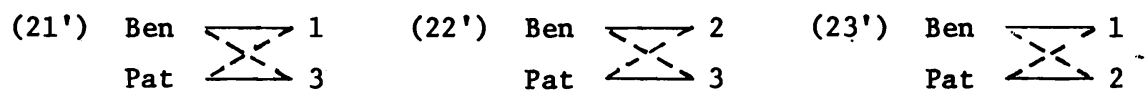

Sentences (c) are irrelevant for this type of representation since they contain only one OAP. In each of the above representations, the highest noncrossing line determines the $O A$ marker which controls the prefix in Kiyaka or the closest $O A$ marker to the verb stem in languages which take more than one OAP; e.g. Shambala; the lowest linking line determines the non-agenito. be Indexed by a full pronoun in Kiyaka, or the second clitic closest to the verb stem in Shambala.

In summary, the facts in (21)-(23) are predicted by the following constraint:

(25) TRANS-HIERARCHICAL' CONSISTENCY CONSTRAINT (THCC)

a. If two potentially active hierarchies are involved in object agreement, a feature higher on the semantic hierarchy (hierarchy 1) may link only to a feature equal or higher than another on hierarchy 2 .

b. Following from (a), the lines which link features on hierarchy 1 to features on hierarchy 2 cannot cross.

There is a rationale behind (25). It is the assumption that each non-agent argument in a clause represents a composite set of features. However, not 
all the features which define the argument under consideration are relevant in the application of a grammatical rule:. In the present case, I am assuming that two (features) hierarchies, one of which is necessarily the $\mathrm{SH}$, are needed to resolve conflicting co-occurrence of OAMs in Kiyaka. We will see later that Shambala also makes use of (25) in similar situations.

Before closing this discussion of the facts described in (21)-(23), I should address one minor point. The analysis I suggest for (21)-(23) seems to have a problem. Specifically, the THCC predicts that two OAMs could be used in the Kiyaka equivalent of "They called you for us". The Kiyaka translation of this sentence should be gramatical since the THCC is fully respected: the benefactive links to the first person, while the patient links to the second person. However, it turns out that such a sentence is not empirically attested in Kiyaka, suggesting that the THCC makes the wrong predction. I will try to show that this is not a case of wrong predictions, but rather, the predictions made by the language independent THCC are just blocked by language specific constraints.

To begin with, remember the following: in order to meet the discourse requirements, a nominal that loses the competition for the control of the OAP must be indexed by a full pronoun. The forms of the different OAMs, including the full pronoun, are provided in Table 1 . In this table, it is crucial to notice that the full pronoun column contains only third person forms. To this effect note that classes 3 to 18 are all third person; for classes 1 and 2 , only third person have full pronouns that function as agreement markers. The column indicates that the language has morphological gaps at the slots reserved for non-third persons. With these facts in mind, we can now see that the THCC has nothing to do with the non-existence of the type of construction given above. Instead, the answer as to why this construction predicted as grammatical by the THCC does not even exist should be found in assuming that the output of the THCC is filtered out by a language specific constraint: the morphological gaps in the present case. Let us now examine one further phenomenon involving two hierarchies in Kiyaka.

object agreement in Kiyaka exhibits a particularly interesting case of interaction between hierarchies: the clash between the semantic hierarchy 
and morphology. As we saw earlier in this paper, prefixation is reserved for agreement with class $1 / 2$ nominals; agreement with the nouns from classes higher than class 2 is expressed by an enclitic, regardless of the semantic role or the animacy status of the nominal. That is, a non-class $1 / 2$ benefactive, recipient, or patient will show agreement by encliticisation. The facts of Kiyaka indicate that a class 7 benefactive, for example, may not prevail over a class $1 / 2$ patient. Let us illustrate this.

(26) a. tu-tel-elé kilawú mu dyaambu dya mwaána

SAwe-call-P madman for lchild

'we called the madman for the child'

b. tu-n'-tel-el-elé-kya kilawú mwaaná

SAwe-1him-call-app1-P-7it madman 1child

'we called the madman for the child'

In the examples above, both non-agent nominals can be indexed in the verb complex, the benefactive mwaaná by prefixation and the patient kilawú by encliticisation. Now observe the examples in (27).

(27) a. tu-tel-elé mwaaná mu dyaambu dya kiláwu

SAwe-call-P 1child for 7madman

'we called the child for the madman'

b. tu-tel-ele-kyá kilawú mu dyaambu dya mwaána

SAwe-call-P-7him 7madman for 1child

'we called the madman for the child'

c. tu-n'-tel-el-elé-kya kilawú mwaaná

'we called the madman for the child'

* 'we called the child for the madman'

Example (27b) Indicates that as far as the patient does not agree with the verb by prefixation, the benefactive can be indexed by encliticisation. However, if the patient is indexed by prefixation at the same time, the resulting sentence is no longer grammatical for the initial reading. The only possible reading of (27c) is that 'madman' is patient and 'child' the benefactive.

The situation in (26) and (27) can only be explained in terms of the mor- 
phology interacting with the semantic hierarchy. As has been convincingly argued by Duranti [1979], the prefix slot is a "high status" position. In terms of the topicality hierarchies system, we have the following ranking: Prefix > Enclitic. At this point, it becomes clear that the constructions in (26) and (27) are also predicted by the constraint (THCC) given in (25), as schematised below.

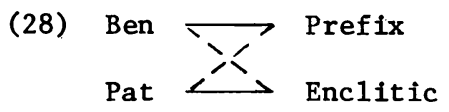

Once again, the non-crossing and solid lines predict the grammaticality of the first reading of (27c), the broken and crossing lines predict the ungrammaticality of the second reading of (27c). Further evidence for the high status of the prefix slot comes from sentences such as those in (19). In these constructions, the nominal which prevails determines the OAP, while the one that loses the competition is obligatorily marked by a full pronoun immediately after the verb.

In this section, I have shown that the outcome of the conflicting predictions by different hierarchies is adequately predicted by the THCC. To close this discussion of hierarchies interaction, I should point out that animacy and humanness are always inactive in Kiyaka.

2.2.2. Shambala. According to $D$, the verb complex can take up to two OAMs in Shambala. The table in (29) shows the sequential orders of potential cooccurring OAMs.

(29) [D's (13)]

\begin{tabular}{|c|c|c|}
\hline A. & 3RD & $2 \mathrm{ND} / 1 \mathrm{ST}$ \\
\hline Bi. & PATIENT & GOAL/BENEFACTIVE \\
\hline Bii. & INS TRUMENT & PATIENT \\
\hline c. & NON-HUMAN & HUMAN \\
\hline D. & PLURAL & SINGULAR \\
\hline
\end{tabular}

VERB STEM

1 1 .

In order to account for conflicting predictions, D proposed the following general principle. 
(30) [D's (14)]

GENERAL STRATEGY FOR CONFLICTING CASES (strong version):

When a conflict arises among the prescribed preferred orders (A)-(D) in (29) [D's (13)], the sequence of clitics is ruled out.

Let us examine (30) as it accounts for the Shambala sentences below. Generally speaking the principle in (30) explains why the (a) sentences are grammatical and why the (b) sentences are not. However, it seems to me that (30) is not explicit enough as to which sequence is well-formed. In order to understand how (30) works, it seems crucially important to refer to the text. Under the constraint I have proposed, it suffices to know the two hierarchles at work and draw the linking lines. In addition, $D^{\prime} s$ principle is labeled "strong version". So it is not surprising that the weaker version given in (31) is needed, for the same language.

(31) [D's (21)]

THE FLEXIBILITY PRINCIPLE:

Low status pronouns are looser about rules than high status pronouns. Note first that (31) denotes a tendency and not a specific rule. Moreover, in the THCC, there is no need for two separate principles. The same constraint contains both of $D^{\prime}$ 's statements. Furthermore, the THCC predicts not only the proper sequential orders or the OAMs, but it also specifies the semantic interpretation of each OA marker. Finally, it follows from the feature linking character of the THCC that the hierarchy with the most distinct positions ( $\mathrm{SH}$ in Kiyaka and Shambala) ${ }^{4}$ is the strongest (or always relevant) hierarchy in the language.

In the following data, it will be observed that all cases of interaction between hierarchies involve the hierarchy of semantic roles with any of the others. This means that any of the other finer distinctions can be neutra1ised. So for example, the humanness hierarchy is neutralised or irrelevant

\footnotetext{
${ }^{4}$ Following Kidima [1984], I am assuming that Kiyaka has at least four positions on the semantic hierarchy: Instrumental < Patient < Recipient < Benefactive.
} 
in (32) since both non-agent arguments are human.

(32) [D's (15)]
a. a-za-m-ni-et-e-a
s/he-PST-him-me-bring-APPL-A
's/he has brought him to me'
*'s/he has brought me to him'
b. *a-za-ni-mw-et-e-a
's/he has brought me to him'
's/he has brought him to me'
c. a-za-ni-eta kwa yeye
s/he-PST-me-bring to him
's/he has brought me to him'

In (32) the semantic and person hierarchies interact in their respective predictions for closeness to the verb stem. According to (25), (32a) is grammatical because it results from a parallel linking while (32b) is ungrammatical since the linking lines cross.

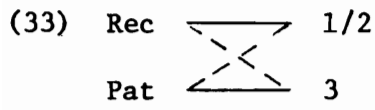

Sentence (32c) shows that for the patient agreement marker to occur immediately before the verb stem, the recipient must be in a prepositional phrase. The relevance of humanness can be observed in (34).

(34) [D's (16)]
a. $n a-i-m w-i t a n g-i-a$
'I call it (meeting) for him'
I-it-him-call-APPL-A
*'I call him for it'
b. ${ }^{*}$ na-mw-i-itang-i-a
I-him-it-ca11-APPL-A
'I call him for it'
'I call it for him'

In these sentences, number and person are irrelevant since both non-agent arguments are third person singular. The respective linkings of (34) are given in (35).

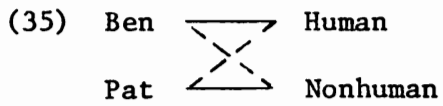

Finally, the number hierarchy can also interact with the semantic hierarchy when the person and humanness hierarchies are irrelevant or neutralised. This is illustrated in (36), where both non-agent arguments are third person human. 
(36) [D's (17)]

$$
\begin{aligned}
& \text { a. a-i-wa-mw-et-e-e 's/he brought them to him' } \\
& \text { s/he-PST-them-him-bring-APPL-A *'s/he brought him to them' } \\
& \text { b. *a-i-mw-wa-et-e-e 's/he brought them to him' } \\
& \text { him-them 's/he brought him to them' } \\
& \text { c. a-i-mw-et-i-e kwa wao 's/he brought him to them' } \\
& \text { s/he-PST-him-bring-PST-A to them }
\end{aligned}
$$

Here again, we can assoctate the grammaticality of (36a) with the parallel lines between both hierarchies in (37) and the ungrammaticality of (36b) with the crossing lines of (37).

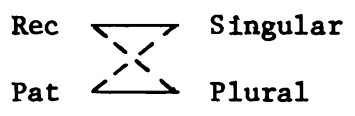

Sentence (36c) indicates that the patient OAP can be close to the verb stem only when the recipient is prepositional

A few things emerge from this discussion of the THCC with regard to Kiyaka and Shambala. First, the THCC neatly predicts the outcome of conflicting co-occurrences of OAMs in both languages. Second, all these cases involve two relevant hierarchies, one of which is always the semantic hierarchy. This supports the primitive status of semantic roles in rules of grammar in general. Finally, it appears that when the THCC is at work, it leaves no room for ambiguity.

2.2.3. Haya. D reports that the verb complex in Haya can take up to four OAPs. However, the investigation of conflicting co-occurring OA markers includes only two OAPs since constructions involving more than two clitics are rare and difficult to process. The preferred sequential orders of the object clitics in Haya are given in (38).

(38) [D's (23)]
A. 3RD
2ND
| $1 S T$
B. INSTRUMENTAL/PATIENT
GOAL/BENEFACTIVE
C. NON-HUMAN
HUMAN
D. PLURAL
SINGULAR
VERB STEM 
D points out that Shambala and Haya use different strategies to deal with conflicting co-occurrences of OA markers. The strategies used in Shambala were discussed above. Haya ranks the features (A)-(D), in accordance with (39).

(39) GENERAL STRATEGY FOR CONFLICTING CASES:

When a conflict arises among any of the prescribed orders in (36)

[D's (23)], rank their status according to the features involved.

Thus in (40)-(42), only the sequences where the OAP corresponds to the $\mathrm{PH}$ are grammatical, because $\mathrm{PH}$ is stronger than $\mathrm{SH}$, or $\mathrm{PH}>\mathrm{SH}$.

Person and Semantic Role [D's (24)-(26)]:

$$
\begin{aligned}
& \text { a. a-ka-mu-n-deet-ela } \\
& \text { he-PST-him-me-bring-APP } \\
& \text { b. *a-ka-n-mu-leet-ela } \\
& \text { me-him }
\end{aligned}
$$

'he brought him to me'

'he brought me to him'

'he brought me to him'

'he brought him to me'

(41) a. a-ka-ku-n-deet-ela he-PST-you/sg-me-bring-APP

'he brought you to me'

'he brought me to you'

b. *a-ka-n-ku-deet-ela me-you/sg

'he brought you to me'

'he brought me to you'

(42)

$$
\begin{gathered}
\text { a. a-ka-mu-ku-leet-ela } \\
\text { him-you/sg } \\
\text { b. *a-ka-ku-mu-leet-ela } \\
\text { him-you/sg }
\end{gathered}
$$

'he brought him to you'

'he brought you to him'

'he brought him to you'

'he brought you to him'

As I mentioned earlier, the strength of a hierarchy is function of the number of its distinct positions. As can be observed in (38), PH is stronger than $\mathrm{SH}$ since the former has three positions and the latter two. In practical terms, SH plays no role in (40)-(42) with regard to the sequential orders of the clitics. Only $\mathrm{PH}$ is relevant. SH remains weak in these constructions and the ranking $\mathrm{SH}<\mathrm{PH}$ means that it will never be relevant in determing the order of the clitics when both are involved and potentially active.

With regard to (43), D gives the same ranking to both $\mathrm{SH}$ and $\mathrm{NH}$, or $\mathrm{SH}=$ $\mathrm{NH}$. 
(43) [D's (27)]
a. a-ka-ba-mu-leet-ela he-PST-them-him-bring-APP
'he brought them to him'
'he brought him to them'
b. a-ka-mu-ba-leet-ela
him-them
'he brought him to them'
*'he brought them to him'

In D's terms, both orders singular-plural (mu-ba) and plural-singular (ba-mu) are grammatical as long as the semantic hierarchy is not violated. We saw in (40)-(42) that in all the grammatical sentences, the order of the clitics is determined exclusively by $\mathrm{PH}$ since we have $\mathrm{SH}<\mathrm{PH}$. In a situation where both hierarchies enjoy equal ranking, we would expect the clitics to interchange orders invariably. However, this does not seem to be the case. In fact, mere ranking is not sufficient because it does not specifically predict the reading of ( $43 \mathrm{~b})$. Under the THCC analysis, one hierarchy (NH) is relevant or active in (43a) and another ( $\mathrm{SH}$ ) is relevant or active in (43b). Thus, (43a) is ambiguous since $\mathrm{SH}$ is neutralised; the reading of (43b) where the $\mathrm{SH}$ is violated is ruled out accordingly.

Humanness is also assigned the same rank as $\mathrm{SH}$, or $\mathrm{HH}=\mathrm{SH}$. This can be observed in (44).

(44) [D's (30)]

$$
\begin{array}{ll}
\text { a. a-ka-bi-ba-leet-ela } & \text { 'he brought them (bi) to them (ba)' } \\
\text { he-PST-them-them-bring-APP } & \text { 'he brought them (ba) to them (bi)' } \\
\text { ( bi = nonhuman; ba = human) } & \\
\text { b. a-ka-ba-bi-l-eta-ela } & \text { 'he brought them (ba) to them (bi)' } \\
& \text { 'he brought them (bi) to them (ba)' }
\end{array}
$$

D explains the ambiguity of (44a) by the possibility of ba- to occupy the slot next to the verb stem because of its semantic role (Goal or Recipient), and because of its humanness feature. The starred reading of (44b) is ruled out since it would violate both the $S$ and $H$ hierarchies. Here again, we can offer the same explanation as in (43). SH < HH does not explicitly predict the reading of (44). If we assume that only one hierarchy is at work at a time, then only HH is relevant in (44a) and only SH in (44b)

So far it appears that where D implies that two hierarchies are active, I suggest that just one hierarchy is, for the purpose of determing the se- 
quential orders of the OAMs. In the same way, I will maintain that only two hierarchies (the maximum) ${ }^{5}$ are relevant where he says that there are three. This suggests that there are probably never more than two hierarchies at work or active at the same time, even though more hierarchies or features may be involved. In the following sentences, $D$ sees the interaction of $P, S$, and $\mathrm{N}$ hierarchies.

Person, Semantic Role and Number [D's (31) and (32)]:

$$
\begin{gathered}
\text { a. a-ka-tu-mu-leet-ela } \\
\text { we-him } \\
\text { b. a-ka-mu-tu-leet-ela } \\
\text { him-us }
\end{gathered}
$$
'he brought us to him'
*' he brought him to us'
'he brought him to us'
'he brought us to hIm'

(46) a. a-ka-tu-ku-leet-ela us-you/sg

b. a-ka-ku-tu-leet-ela you/sg-us
*' 'he brought us to you'
*' he brought you to us'
'he brought us to you'
'he brought you to us'

Duranti suggests the ranking $\mathrm{PH}=\mathrm{SH}+\mathrm{NH}$ for $(45 \mathrm{a})$ and $(46 \mathrm{a})$, and $\mathrm{PH}+\mathrm{SH}>$

${ }^{5}$ The THCC makes an implicit claim that a clause may contain no more than two active hierarchies at the same time. I can only offer some speculative remarks as a rationale for this claim. First, the order of OAMs with regard to the verb stem means contiguity of two and only two items at a time. Thus, the sequential order Pat - Rec - Ben - Verb stem actually reflects the following conflation:

Pat - Rec
Rec - Ben
Ben - Verb Stem

The ordering process of all other hierarchies is also achieved two by two, i.e. it is binary. Second, most hierarchies have only two features. So for instance, in the process of feature matching between the $\mathrm{PH} 3<2<1$ with the $\mathrm{NH} \mathrm{P1<Sg}$, one of the features on the $\mathrm{PH}$ will necessarily link to a feature already linked to another $\mathrm{PH}$ feature:

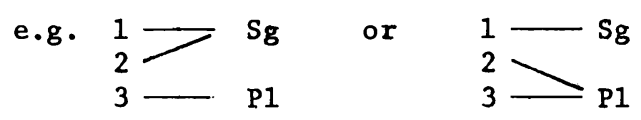

This representation indicates that in this language the $\mathrm{PH}$ is stronger than the $\mathrm{NH}$. 
$\mathrm{NH}$ for (45b) and (46b). It is assumed under the THCC analysis that the sequential orders of OAMs in ambiguous sentences is determined by one relevant hierarchy only (because $\mathrm{SH}$ is weakened). Thus, $\mathrm{SH}$ is inactive in both (45b) and (46b); $\mathrm{PH}$ is active in both. On the other hand, both (45a) and (46a) involve two active hierarchies ( $\mathrm{SH}$ and $\mathrm{NH}$ ) and are therefore predicted by the THCC as shown in (47).

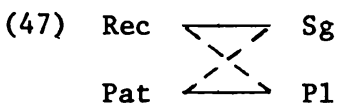

The general picture of the Haya data is summarised in the following table.

$(40)-(42)$

(43)

(43)

(44)

a.

2 hierarchies potentially active: $\mathrm{SH}$ and $\mathrm{HH}$
a. 1 hierarchy actually active : $\mathrm{HH}$

b. 1 hierarchy active

(45)

3 hierarchies potentially active:

a. $\quad 2$ hierarchies actually active

(46)
2 hierarchies potentially active:

1 hierarchy actually active:

2 hierarchies potentially active: $\mathrm{SH}$ and $\mathrm{NH}$

1 hierarchy actually active : $\mathrm{NH}$

: $\mathrm{SH}$ $\rightarrow$ ambiguity

$\rightarrow$ ambiguity

$\rightarrow$ ambiguity

$\mathrm{SH}, \mathrm{PH}$, and $\mathrm{NH}$

$\mathrm{SH}$ and $\mathrm{NH} \rightarrow$ THCC

: $\mathrm{PH} \rightarrow$ ambiguity

3 hierarchies potentially active: $\mathrm{SH}, \mathrm{PH}$, and $\mathrm{NH}$

a. 2 hierarchies actually active : $\mathrm{SH}$ and $\mathrm{NH} \rightarrow$ THCC

b. 1 hierarchy actually active : $\mathrm{PH} \rightarrow$ ambiguity

To close this discussion of Haya, let us observe the three strategies suggested by $D$ still do not account for every construction. Since the ranking of hierarchies is not based on any independent general principle, the result is sometimes contradiction. Thus, D suggests that SH is stronger than $\mathrm{NH}$ in Haya ( $\mathrm{p}$. 37); this statement is contradicted on p. 40. Such contradiction is predictable since $D$ has no principled way of determining the strength of a hierarchy. I have alluded to such a principle earlier and will provide its formulation later. In the same way, there is great confusion about the "violation" of a hierarchy. In $D^{\prime}$ 's account this notion does not always predict ungrammaticality. Consider the following examples. 
(49) [D's (19)]

$$
\begin{aligned}
& a-a-j i-m-k o m-e-a \\
& \text { he-PR-it-him-kil1-APP-A }
\end{aligned}
$$

(50) [D's (20)]

$$
\text { a-a-ji-zi-chinj-i-a 'he slaughters them with it' }
$$

he-PR-it-them-slaughter-APP-A

According to $D$, the sentences illustrate the order Instr - Pat - Verb Stem. He adds the humanness order (Nonhuman - Human - Verb Stem). For (50), he claims that the sentence violates the number hierarchy, and yet the sentence is grammatical. Under the THCC, these constructions are accounted for by the following configuration.

\section{(51) Pat $\longrightarrow$ Animate (Human) \\ Instr

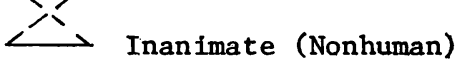

This inconsistency in the use of the notion of violation stems from the implicit belief that a hierarchy is always active. The present analysis has corrected this situation by introducing the distinction between active and inactive hierarchies. The claim is that only active can be violated and the result is always ungrammaticality.

In D's account of Shambala and Haya, these two languages use very different strategies in case of conflicting predictions by different hierarchies. The present analysis reduces this difference to the nature of the $\mathrm{SH}$ and therefore the relative importance of THCC in these languages. THCC is thus crucial in resolving conflicting co-occurrences of OAMs. So in spite of the fact that Haya mostly uses a single hierarchy to determine the sequential order of OAMs, it still refers to the THCC in some cases. It also appears that whenever the $\mathrm{SH}$ is not active, ambiguity occurs. In the same way, whenever the SH is active no ambiguity is possible. The claim here is that this generalisation holds for Kiyaka, Shambala, and Haya, in spite of the apparent differences in the strategies these languages use to handle multiple agreement.

2.3. Implications. The discussion of multiple agreement in Kiyaka, Shamba- 
$1 a$, and Haya has established the crucial role of the SH and the THCC in case of conflicting co-occurrences of object agreement markers. It emerges that the apparent differences in the strategies used by Kiyaka and Shambala on one hand and Haya on the other can be explained by the relative strength of the SH in these languages. Thus we can safely hypothesise that languages fall into two major types in terms of the strategies they use to resolve conflicting co-occurrences of OAMs.

(49) Strategies for Resolving Conflicting Co-occurrences of OAMs Type-1 languages, e.g. Kiyaka, Shambala:

Strong version of THCC

Always use THCC: 2 hierarchies, one of which is always the SH; no ambiguity.

Type-2 languages, e.g. Haya:

Weak version of THCC

Mostly use one hierarchy: the predominant hierarchy is the one which is different from SH; ambiguity always results since the $\mathrm{SH}$ is inactive or neutralised.

Strong version of THCC

Sometimes use THCC: 2 hierarchies, the $\mathrm{SH}$ and any hierarchy; no ambiguity because the $\mathrm{SH}$ is active.

The cholce between the strong and the weak version in type 2 languages depends on whether the $\mathrm{SH}$ is active or not. Once again, it is significant that only the SH can be specifically predicted as active or inactive. The predominant hierarchy cannot be predicted if it is different from the $\mathrm{SH}$. Determining the predominant hierarchy in type-2 languages is a language specific matter. Thus, the $\mathrm{PH}$ takes precedence over the SH in Haya [Duranti 1979], and the $\mathrm{AH}$ hierarchy is predominant in Shona, according to Hawkinson and Hyman [1974].

Finally, this investigation would be incomplete if we did not address the following question: what is a strong or predominant hierarchy? In other words, we need a principled way for determining the predominant hierarchy, since, as I mentioned earlier, it is a language specific process especially in type-2 languages. I suggested earlier that the strength of a hierarchy 
is function of the number of distinctive featuers in the hierarchy. So the principle to refer to in order to find the predominant hierarchy in a language can be formulated as follows.

(50) PREDOMINANT HIERARCHY PRINCIPLE

a. The predominant hierarchy in a language is the one with the highest number of distinctive features.

b. If the highest number of distinctive features is shared by the $\mathrm{SH}$ and another hierarchy, the $\mathrm{SH}$ is predominant in virtue of its inherent status as reflected in (49).

The rationale behind this principle is as follows. It is significant to observe that even if a verbal unit contains three or more OAMs, only two of these can be contiguous at a time. That means that the sequentlal order of OAMs is determined two by two, as reflected by the THCC and shown in footnote 5 .

The view I offer here for the strength of a hierarchy makes at least one prediction. The conflation Person-Animacy (PA) (1st > 2nd > 3rd Human > 3rd Animal > 3rd Inanimate) common in the topicality 1iterature, e.g. Duranti and Hyman [1982], is questionable, especially when dealing with a particular rule of grammar. Fortunately, Duranti and Hyman do mention in a footnote (p. 232) that the PA should be separated into two parts, $\mathrm{PH}$ and $\mathrm{AH}$, on the basis of the Haya data. Still, it seems that the separation they recommend is limited to Haya and does not reflect the cases where $\mathrm{AH}$ is predominant. I simply suggest that conflation of hierarchies be avoided, unless there is evidence for it.

\section{Conclusion}

This investigation of the facts of $O A$ in Kiyaka has revealed that the data raise two theoretical problems and that they can be adequately addressed by referring to the notion of topicality hierarchy. The first problem concerns the control of the only avallable object prefix slot when more than one non-agent nominal agrees with the verb to meet discourse requirements. I have suggested that the semantic hierarchy Benefactive > Recipient > Patient takes care of the situation.

The second problem raised by the data is central to all studies that have 
referred to topicality hierarchies in the investigation of Bantu OA: what happens when different hierarchies make contradictory and conflicting predictions for the control of the OAMs? In my attempt to address this question, a review of a similar attempt by Duranti reveals a too rigid view of the role of hierarchies. Duranti does indeed give the impression that hierarchies which have been established in a language are always active in that language. The inevitable consequence of such a conception of hierarchies is the confusion and contradictions characteristic of Duranti's discussion of Shambala and Haya. This paper has proposed a different conception of the role of hierarchies in determining the sequential order of OAMs.

The main points to distinguish under the new view are the following. Different features of the topicality hierarchies are always involved in the rules of grammar in general. However, involvement of such features in grammatical rules does not necessarily entail any active role of these features in the rules. In fact, a hierarchy can be established and active in one construction, but the same hierarchy can still be neutralised and thus inactive in another construction in the same language. Also, a hierarchy can be active and respected in a construction, and yet the same hierarchy can be active and violated in another construction because only active hierarchies can be violated and therefore yield ungrammatical constructions.

Duranti's study ranks the different hierarchies without addressing the question of what determines the strength of a hierarchy. The principle proposed in this paper provides a potential for a cross-Bantu explanation of the role of hierarchies. Thus, defining the strength of a hierarchy in terms of the different distinct positions on a hierarchy clearly indicates that the $\mathrm{SH}$ has the biggest potential. Accordingly, whether SH is predominant or not in a language, the language will use one or the other version of the THCC. In this new view, ambiguity resulting from multiple object agreement can also be predicted on the basis of the relative strength of the SH in the language, without any reference to particular constructions.

The typology proposed in this paper should be understood as a hypothesis, since the problem of interacting hierarchies has been addressed only in the three languages covered in this paper. More empirical data from a variety 
of languages are needed to check the validity of the typology suggested in the present study; and that is of course to be addressed in subsequent research. Future research should probably start with the inventory of hierarchies of individual languages. The different languages would then be regrouped with regard to their relative strength of the SH. An in depth investigation should be carried out in languages where either the $\mathrm{PH}$ or the $\mathrm{AH}$ are predominant to determine their similarities and differences with regard to the SH. A less important but still interesting task would be to check whether PH or AH predominant languages can be further subdivided into smal1er groups according to the way they resolve conflicting co-occurrences of object agreement markers. 


\section{REFERENCES}

Chafe, W.F. 1976. "Givenness, contrastiveness, definiteness, subjects and topics." In Charles M. Li (ed.), Subject and Topic, pp. 27-55. New York: Academic Press.

Clark, H. and E. Clark. 1977. Psychology and Language: an Introduction to Psycholinguistics. New York: Harcourt Brace Jovanovich, Inc.

Dik, S. 1980. Functional Grammar. Amsterdam: North-Holland.

Duranti, A. 1979. "Object clitic pronouns in Bantu and the Topicality Hierarchy." Studies in African Linguistics 10:31-46.

Foley, W. and R. Van Valin, Jr. 1984. Functional Syntax and Universal Grammar. Cambridge: Cambridge University Press.

Givón, T. 1971. "Historical syntax and synchronic morphology: an anthropologist's fleld trip." Chicago. Linguistic Society 7:349-415.

Givón, T. 1976. "Topic, pronoun, and grammatical agreement." In Charles M. Li (ed.), Subject and Topic, pp. 149-188. New York: Academic Press.

Hawkinson, A. and L. Hyman. 1974. "Hierarchies of natural topic in Shona." Studies in African Linguistics 5:147-170.

Hopper, P. and S. Thompson. 1980. "Transitivity in grammar and discourse." Language 56:251-299.

Hyman, L. and A. Duranti. 1982. "On the object relation in Bantu." In P. Hopper and S.A. Thompson (eds.), Syntax and Semantics 15: Studies in Transitivity, pp. 217-239. New York: Academic Press.

Kidima, L. 1983. "Focus and word order in Kiyaka simplex clauses." Unpublished paper. University of Pittsburgh.

Kidima, L. 1984. "Objects and object agreement in Kiyaka." Unpublished M.A. thesis, University of Pittsburgh.

Kisseberth, D.W. and M.I. Abasheikh. 1977. "The Object Relationship in Chimwi:ni, a Bantu language." In P. Cole and J. Sadock (eds.), Syntax and Semantics 8: Grammatical Relations, pp. 179-218. New York: Academic Press.

Marantz, A. 1984. The Nature of Grammatical Relations. Cambridge, MA: MIT Press.

Trithart, L. 1979. "Topicality: an alternative to the Relational View of Bantu Passive." Studies in African Linguistics 10:1-30.

Van den Eynde, K. 1968. Eléments de Grammaire Yaka. Kinshasa: Presses Universitaires. 
